Www.jmscr.igmpublication.org

Impact Factor (SJIF): 6.379

Index Copernicus Value: 79.54

ISSN (e)-2347-176x ISSN (p) 2455-0450

crossrefDOI: https://dx.doi.org/10.18535/jmscr/v6i10.64

Journal Of Medical Science And Clinical Research

IGM Publication

An Official Publication of IGM Publication

\title{
Endobronchial Carcinoid Tumours - A Case Series and review of Literature
}

\author{
Authors \\ Dr Rajesh V ${ }^{1}$, Dr Melcy Cleetus ${ }^{1}$, Dr Jolsana Augustine**1, Dr Divya $\mathbf{R}^{1}$, \\ Dr Sunitha Thomas ${ }^{2}$, Dr Latha Abraham ${ }^{2}$ \\ ${ }^{1}$ Department of Pulmonary Medicine, ${ }^{2}$ Department of Pathology, Rajagiri Hospital, Aluva \\ Corresponding Author \\ Dr Jolsana Augustine \\ Consultant Pulmonologist, Dept of Pulmonary Medicine, Rajagiri Hospital, Aluva, Kerala, 683112, India \\ Email: j_augustine08@ymail.com, Mobile number: 9446728953,0484- 29055039
}

\begin{abstract}
Bronchial carcinoid tumors are neuroendocrine neoplasms. The spectrum can range from low-grade typical carcinoids to more aggressive atypical carcinoids. Most bronchial carcinoids are located in central airways, hence clinical features and radiologic findings are usually related to bronchial obstruction. The aim of the present study was to describe the presenting clinical features, radiological findings, histological features, treatment modalities and outcome in pulmonary carcinoid tumours diagnosed in a tertiary care institute in Kerala, South India. This was a retrospective observational study of all cases of pulmonary carcinoids that presented to the Pulmonary Medicine department of our institute between August 2015 to July 2018. The clinical presentation, radiological features, stage of disease, histology, treatment instituted and survival was noted from the electronic medical case records. 8 cases of lung carcinoid tumours were encountered during the study period. The mean age of study subjects was 50.6 years. Equal sex predilection was noted. Lower lobes were involved most frequently and right side was affected commoner than the left. Hemoptysis, recurrent respiratory infections and lobar / segmental collapse were the common clinical presentations. All patients had their diagnosis established by bronchoscopic biopsy. Carcinoid tumors accounted for 0.33 percent of pulmonary admissions in the present study. Most of the lesions were central. Symptoms of airway involvement dominated the clinical and radiological presentation. All except one case was subjected to surgical resection with no mortality noted during the study period and follow up.
\end{abstract}

Keywords: bronchial carcinoid, bronchoscopy, lung tumor, neuroendocrine tumor.

\section{Introduction}

Endobronchial carcinoid tumors constitute an uncommon group of pulmonary neoplasms. Carcinoid lung tumors represent the most indolent form of a spectrum of bronchopulmonary neuroendocrine tumors (NETs). ${ }^{(1)}$
Carcinoid tumors account for $0.5-2.5 \%$ of all primary lung tumors. ${ }^{(2)}$ It is a low-grade malignant neoplasm believed to be derived from surface of bronchial glandular epithelium. Most of them have a central location, thereby producing symptoms and signs of bronchial obstruction such as localized wheeze, non resolving recurrent 
pneumonitis, cough, chest pain, and fever. Hemoptysis is present in approximately $50 \%$ of the cases due to hypervascularity ${ }^{(3)}$. Between $25 \%$ and $39 \%$ of patients with a carcinoid pulmonary tumor are asymptomatic.

As NETs, carcinoids are capable of producing a variety of biologically active peptides and hormones, including serotonin, adrenocorticotropic hormone (ACTH), antidiuretic hormone $(\mathrm{ADH})$, melanocyte-stimulating hormone (MSH), and others. Excess serotonin production has been implicated in the development of carcinoid syndrome. This syndrome is characterized by a constellation of symptoms, including tachycardia, flushing, bronchoconstriction, hemodynamic instability, diarrhea, and acidosis. Carcinoid syndrome occurs in about $2 \%$ of cases of pulmonary carcinoid tumors. It is more frequently noted in cases associated with GI carcinoid tumors. $^{(4)}$

Carcinoid tumors of the lung generally have a better prognosis than other forms of pulmonary malignancy. They have an overall 5-year survival rate of $78-95 \%$ and a 10 -year survival rate of 77 $90 \%$. Typical carcinoid tumors have been found to have a much better prognosis than do the atypical variety. ${ }^{(5)}$ The treatment of carcinoid tumours is essentially surgical as long as the tumours come under a resectable stage and the subject has operative fitness. Regardless of histologic type, the presence of lymph node metastases at the time of resection has a significant effect on prognosis in many series. ${ }^{(6)}$ Herein we give a detailed review of literature and our own single centre experience regarding diagnosis and management of carcinoid.

\section{Materials and Methods}

This was a retrospective observational descriptive single centre study carried out in a tertiary care centre in Kochi, Kerala, South India. The study period extended from August 2015 to July 2018. All subjects attending the out-patient department or in-patient care of the Pulmonary Medicine department were scrutinized and their diagnosis was retrieved from the electronic medical records
(EMR). All subjects with a diagnosis of bronchial carcinoids were included in the study. The clinical presentation, radiological features, diagnostic modality employed to establish the diagnosis, therapy instituted and follow up survival was noted from the medical records.

\section{Results}

8 cases of bronchial carcinoid tumours were encountered in the study period. The mean age of study subjects was 50.6 years with the age at presentation varying from 21 years to 72 years. Males and females were equally affected. The involvement was right sided in 5 out of 8 patients and lower lobes were involved in 62.5 percent of subjects. Table 1 summarises the details of study subjects.

All the subjects had their lesion located in the central airways between the second to fourth generations of airways. The presenting symptoms included hemoptysis, recurrent respiratory infections and cough. Table 2 summarises the patient symptoms. Bronchoscopic biopsy with histopathology complemented by immunohistochemistry established the diagnosis in all cases. All the subjects had typical carcinoid tumour. All subjects had stage 1 or 2 disease and none of them had features of carcinoid syndrome. One subject was lost to follow up after diagnosis. All the rest had surgical resection of their lesion and are surviving till date. The longest period of follow up has been 33 months.

Figure 1,2,3 depicts the chest radiograph and CT chest of a patient with right lower lobe carcinoid. Figure 4,5,6 shows the histopathology of a subject's resected specimen showing features of typical carcinoid. 


\section{JMSCR Vol||06||Issue||10||Page 377-383||October}

Table 1- Summarises baseline characteristics of study population $(n=8)$ and synopsis of the compiled data

\begin{tabular}{|l|c|c|c|c|c|}
\hline Age / Sex & $\begin{array}{c}\text { Location } \\
\text { (Side / Lobe) }\end{array}$ & $\begin{array}{c}\text { Location } \\
\text { (airway generation) }\end{array}$ & Diagnostic technique & Therapy & Survival \\
\hline 41/ Female & Right & Right main bronchus & Bronchoscopic biopsy & Right pnuemonectomy & Till date \\
\hline 64/Female & Right & Right lower lobe bronchus & Bronchoscopic biopsy & Right lower lobectomy & Till date \\
\hline 21/Female & Right & Right lower lobe bronchus & Bronchoscopic biopsy & Right lower lobectomy & Till date \\
\hline 65/Male & Left & Left lower lobe bronchus & Bronchoscopic biopsy & Medical management & Lost to follow up \\
\hline 58/Male & Left & Left main bronchus & Bronchoscopic biopsy & Left pnuemonectomy & Till date \\
\hline 36/Female & Right & Right main bronchus & Bronchoscopic biopsy & Right pnuemonectomy & Till date \\
\hline 48/Male & Right & Right lower lobe bronchus & Bronchoscopic biopsy & Right lower lobectomy & Till date \\
\hline 72/Male & Left & Left lower lobe bronchus & Bronchoscopic biopsy & Left lower lobectomy & Till date \\
\hline
\end{tabular}

Table 2 Symptomatology of the study population

\begin{tabular}{|l|c|c|}
\hline Symptoms & $\begin{array}{c}\text { Number of } \\
\text { patients }\end{array}$ & Percentage \% \\
\hline Hemoptysis & 5 & 62 \\
\hline $\begin{array}{l}\text { Recurrent respiratory } \\
\text { infection }\end{array}$ & 4 & 50 \\
\hline Collapse & 3 & 37 \\
\hline Fever & 1 & 12 \\
\hline Carcinoid syndrome & 0 & 0 \\
\hline
\end{tabular}
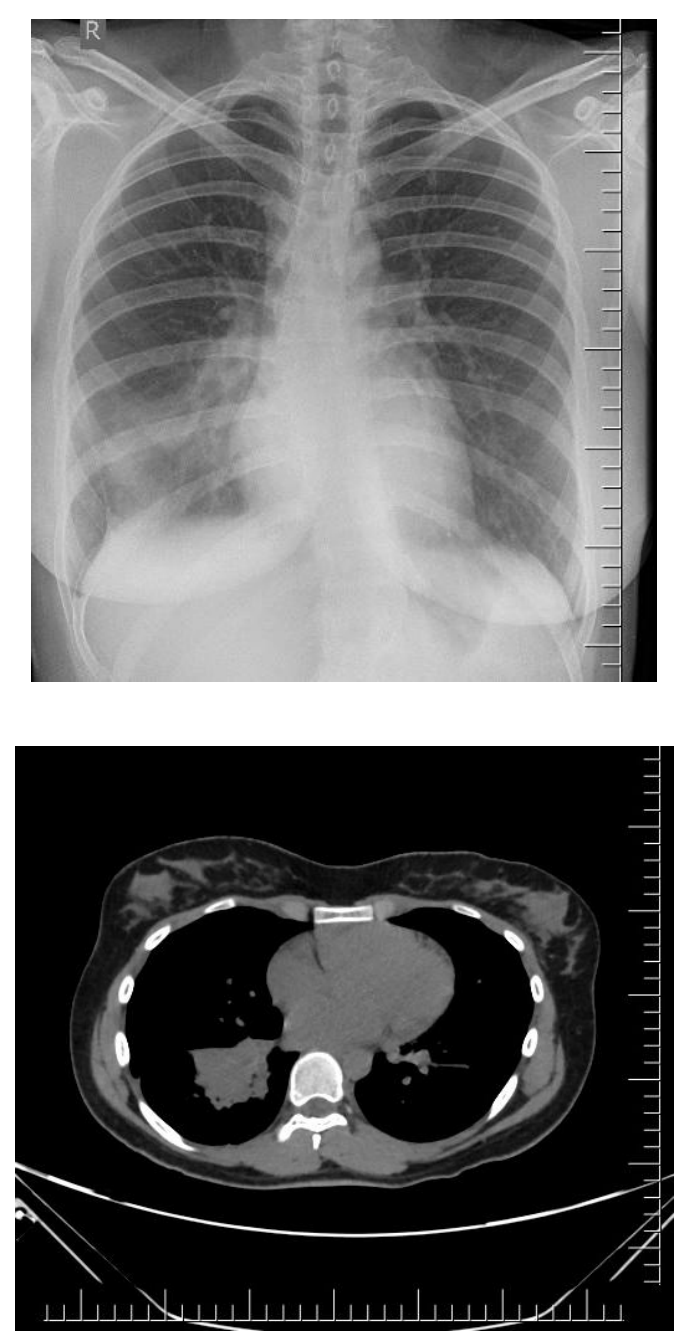

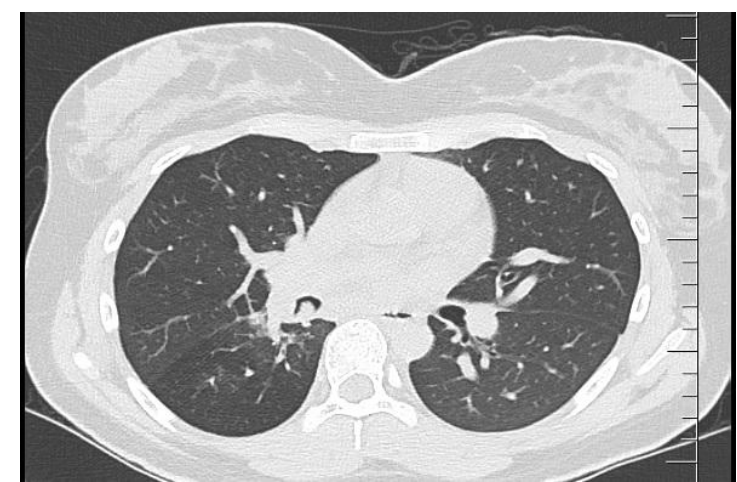

Figures 1, 2 and 3 Chest radiograph and representative CT images of a patient with right lower lobe carcinoid tumour

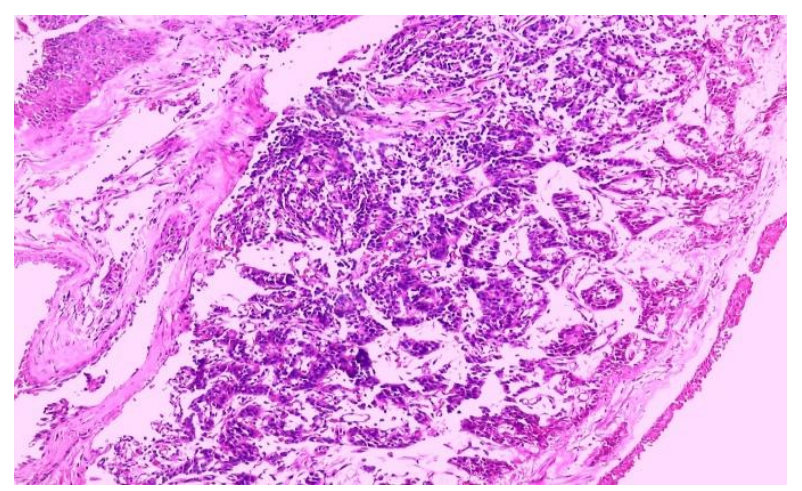

Figure 4 Bronchoscopic biopsy (H\&E, 100x) showing arrangement of tumor cells in nests, trabeculae and pseudogladular pattern

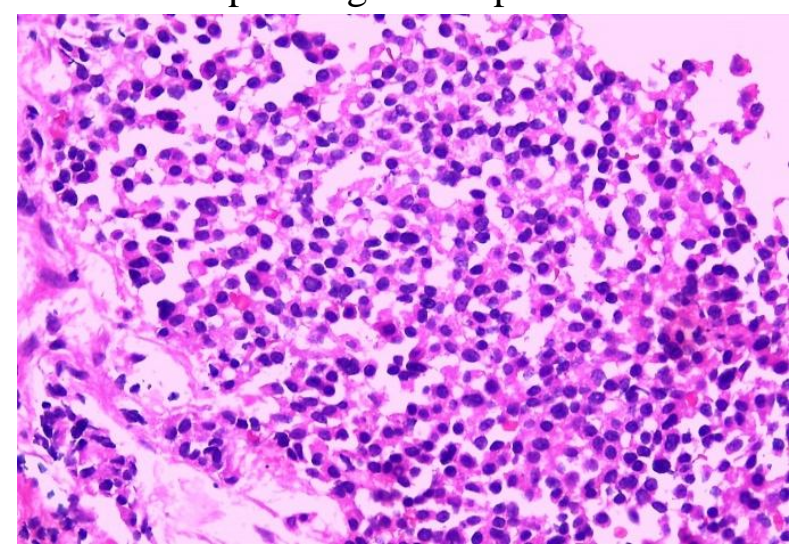

Figure 5 H\&E, 400x - tumor cells with round nuclei, fine stippled chromatin and granular eosinophilic cytoplasm 


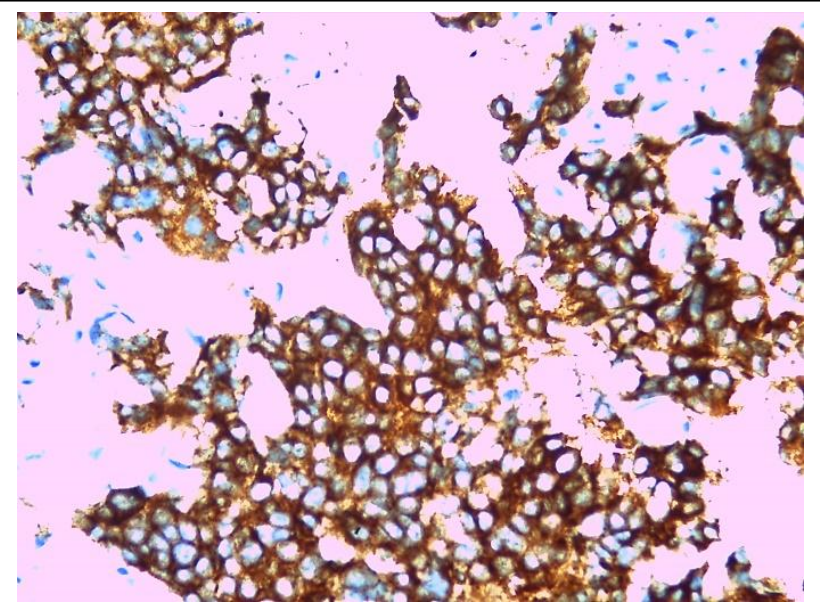

Figure 6 Synaptophysin (IHC 400 x) demonstrating strong cytoplasmic positivity

\section{Discussion}

The earliest description of carcinoid tumour dates back to the late 19th century. Lubarsh found multiple tumors in the small bowel of 2 patients at autopsy and gave a detailed data in his publication in $1888 .^{(7)}$ Siegfried Oberndorfer, a German pathologist at the University of Munich, coined the term karzinoide, or "carcinoma-like", to describe the unique feature of behaving like a benign tumor despite having a malignant appearance microscopically. Its ability to secrete bioactive chemicals was later described by Gosset and Masson in $1914^{(8)}$. Hamperl in 1937 gave the first description of pulmonary carcinoid ${ }^{(9)}$.

Carcinoid tumors have an estimated incidence of 1 to 2 cases per 100,000 individuals in the United States $^{(10)}$ and similar figures are quoted from European studies as well ${ }^{(11)}$. Population based incidence studies are lacking in India. A recent analysis of 13,715 carcinoid tumors revealed that more than two-third of all carcinoid tumors originate in the digestive tract and one fourth originate in relation to the airways or pulmonary parenchyma. $^{(12)}$

The etiopathogenesis of carcinoid tumours is largely unclear. No known carcinogens or exposure to environmental agents has been unequivocally implicated in carcinogenesis. Although the association between bronchial carcinoids and smoking is unclear, between onethird and two-thirds of all patients have been smokers with higher prevalence of smoking being reported in patients with atypical carcinoids. ${ }^{(13)}$ Multiple endocrine neoplasia type 1 (MEN1) is an autosomal dominant syndrome which occurs from an inactivating mutation on a tumor suppressor gene located on chromosome11. If an individual presents with two or more primary MEN1-associated endocrine tumors like parathyroid adenoma/hyperplasia, gastroenteropancreatic tumor, and pituitary adenoma the diagnosis of MEN1 can be established. In addition, they may have adrenal, bronchial carcinoid, thymiccarcinoid (TC) and skin tumors also. A study based on 36 year Mayo clinic experience states an incidence of bronchial carcinoids in approximately 4.9 percent of MEN 1 cases $^{(14)}$.

Most series on lung carcinoid tumours have reported an equal incidence among either gender, with the incidence peaking in the fifth decade. The patients of carcinoid most commonly presents with hemoptysis, cough, recurrent pulmonary infections, fever, chest discomfort, unilateral wheezing and shortness of breath. ${ }^{(15)} 25$ to $40 \%$ of patients are asymptomatic. Carcinoid syndrome, which occurs when the vasoactive substances escape into the systemic circulation escaping the hepatic degradation, is seen in less than $5 \%$ of patients with pulmonary carcinoid. ${ }^{(16)}$

The proportion of subjects with central versus peripheral carcinoid tumours of the lung have varied in different large series. In the series by Hurt and Bates, ${ }^{(3)} 97 \%$ of the lesions were central as opposed to only $55 \%$ in the study by Harpole et al. ${ }^{(17)}$. A lesser degree of variability has been noted in the occurrence of typical versus atypical carcinoid tumours, with typical carcinoids accounting for $99 \%$ in the report by Hurt and Bates versus $66 \%$ in the study by Harpole et al. Most other studies have observed typical carcinoid lesions accounting for $70-90 \%$ of cases. ${ }^{(18)}$ Right middle lobe involvement was very common in two of the large reported series, ${ }^{(13)(19)}$ which is in contrast with Okike et $\mathrm{al}^{(20)}$ in which the most common sites of tumors were the right and left lower lobes. 
There is no separate staging scheme for lung carcinoid tumours and the TNM staging for nonsmall cell lung carcinoma applies to these tumours also. Regional nodal involvement in typical carcinoid (TC) tumors is low ${ }^{(21)}$ and ranges from 3 to $20 \%$, unlike the atypical carcinoids (AC), in which nodal metastasis ranges from 48 to $75 \%$. Distant metastases are quite rare in the typical group, but quite common in the atypical group. ${ }^{(22)}$ The standard treatment for TC and AC is surgical resection. ${ }^{(23)(24)(25)}$. Carcinoid tumours harbour a malignant potential (AC being more malignant than TCs). A 'tip of the iceberg' growth has been postulated in cases of carcinoid tumors, wherein the visible intraluminal part might just be a tinyfraction of tumour growing from deeper inside the tracheobronchial wall. ${ }^{(26)}$ Resection margins could not be checked forresidual tumour and sampling of lymph nodes is not possible with bronchoscopic tumor resection proedures. Hence subjecting patients to non-surgical resection by relatively less-invasive options like bronchoscopic treatment was deemed unacceptable. However, advancements in diagnostic and therapeutic modalities and better understanding of tumor biology $y^{(26)(27)}$ has encouraged interventional pulmonologists to explore less or minimally therapeutic techniques for optimal preservation of healthy lung tissue.

There have been reports that initial bronchoscopic treatment (IBT) to be a justifiable approach for bronchial carcinoids instead of immediate surgical exploration and resection. ${ }^{(28)}$ Moreover, recent literature showed favourable results for bronchoscopic treatment (BT) in carefully selected patients. ${ }^{(29)}$

There has traditionally been no systemic chemotherapeutic agents for the treatment of carcinoid tumour. In February 2016, Everolimus was approved by the US Food and Drug Administration (FDA) for progressive, welldifferentiated, nonfunctional neuroendocrine tumors (NETs) of lung origin that are unresectable, locally advanced, or metastatic. Approval was based on the RADIANT-4 trial, ${ }^{(30)}$ in which median progression-free survival was 11 months in the 205 patients allocated to receive everolimus (10 mg/day) and 3.9 months in the 97 patients who received placebo. Everolimus was associated with a $52 \%$ reduction in the estimated risk of progression or death. Somatostatin receptor Analogues (SSA) such as octreotide and lanreotide are primarily used for controlling symptoms associated with carcinoid syndrome.

The outcome in successfully resection carcinoid tumours of the lung is excellent. Following resection of the tumor, 5-year survival rate of $94 \%$ was observed in 1109 patients with Typical Carcinoids by The European Society of Thoracic Surgeons Neuroendocrine Tumors Working Group $^{(31)(22)}$ and 3 year survival rate of $67 \%$ was observed in the United States by a database analysis of 441 patients with AC. ${ }^{(32)}$

Further advancements in therapy of carcinoid tumors other than surgical procedures may evolve in coming years.

\section{Limitations of the study}

Our study is a single centre study with limited number of study subjects. The limited number of cases diagnosed within the relatively long study period of 3 years is a reflection of the fact that this is an uncommon disease in general population. The study was undertaken in a retrospective fashion and data were recorded from the electronic medical records. However, the presence of a robust EMR system circumvents the drawbacks of retrospective data collection. Updation of patient data was done by telephonic consults to identify follow up status of subjects who lacked clinical visits in the last 6months.

\section{Conclusions}

Pulmonary carcinoids are uncommon tumours in pulmonary practice and are accounted for 8 cases of lung carcinoid tumours were encountered during the study period. The mean age of study subjects was 50.6 years. Equal sex predilection was noted. Lower lobes were involved most frequently and right side was affected commoner 
than the left. Hemoptysis, recurrent respiratory infections and lobar / segmental collapse were the common clinical presentations. Radiologically, all the lesions were central. All patients had their diagnosis established by bronchoscopic biopsy and all except one had surgical resection. No mortality was observed in the treatment or follow up period.

Financial support and sponsorship - Nil

No conflicts of interest

\section{References}

1. Warren WH, Gould VE, Faber LP, Kittle CF, Memoli VA. Neuroendocrine neoplasms of the bronchopulmonary tract. A classification of the spectrum of carcinoid to small cell carcinoma and intervening variants. J Thorac Cardiovasc Surg. 1985 Jun;89(6):819-25.

2. Bhatia K, Ellis S. Unusual lung tumours: an illustrated review of CT features suggestive of this diagnosis. Cancer Imaging. 2006 Jul 4;6(1):72-82.

3. Hurt R, Bates M. Carcinoid tumours of the bronchus: a 33 year experience. Thorax. 1984 Aug 1;39(8):617-23.

4. Han B, Sun J-M, Ahn JS, Park K, Ahn MJ. Clinical outcomes of atypical carcinoid tumors of the lung and thymus: 7-year experience of a rare malignancy at single institute. Med Oncol. 2013 Mar;30(1):479.

5. Zhong CX, Yao F, Zhao H, Shi JX, Fan LM. Long-term outcomes of surgical treatment for pulmonary carcinoid tumors: 20 years' experience with 131 patients. Chin Med J (Engl). 2012 Sep;125(17):3022-6.

6. Cardillo G, Sera F, Di Martino M, Graziano P, Giunti R, Carbone L, et al. Bronchial carcinoid tumors: nodal status and long-term survival after resection. Ann Thorac Surg. 2004 May;77(5):1781-5.

7. Lubarsh O. Uber den pimaeren krebs des ileum nebst Bemerkungen ueber das gleichzeitige Vorkommen von krebs und
Tuberculos. Virchows Arch. 1888;(11): 280-317.

8. Gosset A, Masson P. Tumeurs endocrines de l'appendice. Presse Med. 1914; (25):237-9.

9. Hamperl H. Uber gutartige bronchialtumoren (cylindrome und carcinoide). Virchows Arch. 1937;(300):46-88.

10. Modlin IM, Sandor A. An analysis of 8305 cases of carcinoid tumors. Cancer. 1997 Feb 15;79(4):813-29.

11. Newton JN, Swerdlow AJ, dos Santos Silva IM, Vessey MP, Grahame-Smith DG, Primatesta P, et al. The epidemiology of carcinoid tumours in England and $\begin{array}{lllll}\text { Scotland. } & \mathrm{Br} & \mathrm{J} & \text { Cancer. } & 1994\end{array}$ Nov;70(5):939-42.

12. Modlin IM, Lye KD, Kidd M. A 5-decade analysis of 13,715 carcinoid tumors. Cancer. 2003 Feb 15;97(4):934-59.

13. Fink G, Krelbaum T, Yellin A, Bendayan D, Saute M, Glazer M, et al. Pulmonary Carcinoid: Presentation, Diagnosis, and Outcome in 142 Cases in Israel and Review of 640 Cases From the Literature. CHEST. 2001 Jun 1;119(6):1647-51.

14. Singh Ospina N, Thompson GB, C. Nichols F, D. Cassivi S, Young WF. Thymic and Bronchial Carcinoid Tumors in Multiple Endocrine Neoplasia Type 1: The Mayo Clinic Experience from 1977 to 2013. HORM CANC. 2015 Dec $1 ; 6(5): 247-53$.

15. Dusmet ME, McKneally MF. Pulmonary and thymic carcinoid tumors. World J Surg. 1996 Feb;20(2):189-95.

16. Hasleton PS. Histopathology and prognostic factors in bronchial carcinoid tumours. Thorax. 1994 Sep;49 (Suppl):S56-62.

17. Harpole DH, Feldman JM, Buchanan S, Young WG, Wolfe WG. Bronchial carcinoid tumors: A retrospective analysis of 126 patients. The Annals of Thoracic Surgery. 1992 Jul;54(1):50-5. 
18. McCaughan BC, Martini N, Bains MS. Bronchial carcinoids. Review of 124 cases. J Thorac Cardiovasc Surg. 1985 Jan;89(1):8-17.

19. Ranchod M, Levine GD. Spindle-cell carcinoid tumors of the lung: a clinicopathologic study of 35 cases. Am J Surg Pathol. 1980 Aug;4(4):315-31.

20. Okike N, Bernatz PE, Woolner LB. Carcinoid Tumors of the Lung. :8.

21. Davila DG, Dunn WF, Tazelaar HD, Pairolero PC. Bronchial carcinoid tumors. Mayo Clin Proc. 1993 Aug;68(8):795803.

22. Caplin ME, Baudin E, Ferolla P, Filosso P, Garcia-Yuste M, Lim E, et al. Pulmonary neuroendocrine (carcinoid) tumors: European Neuroendocrine Tumor Society expert consensus and recommendations for best practice for typical and atypical pulmonary carcinoids. Ann Oncol. 2015 Aug;26(8):1604-20.

23. Detterbeck FC. Management of carcinoid tumors. Ann Thorac Surg. 2010 Mar;89(3):998-1005.

24. Filosso PL, Rena O, Donati G, Casadio C, Ruffini E, Papalia E, et al. Bronchial carcinoid tumors: surgical management and long-term outcome. J Thorac Cardiovasc Surg. 2002 Feb;123(2):303-9.

25. Marty-Ané CH, Costes V, Pujol JL, Alauzen M, Baldet P, Mary H. Carcinoid tumors of the lung: do atypical features require aggressive management? Ann Thorac Surg. 1995 Jan;59(1):78-83.

26. Travis WD, Rush W, Flieder DB, Falk R, Fleming MV, Gal AA, et al. Survival analysis of 200 pulmonary neuroendocrine tumors with clarification of criteria for atypical carcinoid and its separation from typical carcinoid. Am J Surg Pathol. 1998 Aug;22(8):934-44.
27. Skov BG, Krasnik M, Lantuejoul S, Skov T, Brambilla E. Reclassification of neuroendocrine tumors improves the separation of carcinoids and the prediction of survival. J Thorac Oncol. 2008 Dec;3(12):1410-5.

28. van Boxem TJ, Venmans BJ, van Mourik JC, Postmus PE, Sutedja TG. Bronchoscopic treatment of intraluminal typical carcinoid: a pilot study. J Thorac Cardiovasc Surg. 1998 Sep;116(3):402-6.

29. Brokx HAP, Paul MA, Postmus PE, Sutedja TG. Long-term follow-up after first-line bronchoscopic therapy in patients with bronchial carcinoids. Thorax. 2015 May;70(5):468-72.

30. Yao JC, Fazio N, Singh S, Buzzoni R, Carnaghi C, Wolin E, et al. Everolimus for the treatment of advanced, non-functional neuroendocrine tumours of the lung or gastrointestinal tract (RADIANT-4): a randomised, placebo-controlled, phase 3 study. Lancet. $2016 \quad$ Mar 5;387(10022):968-77.

31. Filosso PL, Guerrera F, Evangelista A, Welter S, Thomas P, Casado PM, et al. Prognostic model of survival for typical bronchial carcinoid tumours: analysis of 1109 patients on behalf of the European Association of Thoracic Surgeons (ESTS) Neuroendocrine Tumours Working Group. Eur J Cardiothorac Surg. 2015 Sep;48(3):441-7; discussion 447.

32. Steuer CE, Behera M, Kim S, Chen Z, Saba NF, Pillai RN, et al. Atypical carcinoid tumor of the lung: a surveillance, epidemiology, and end results database analysis. J Thorac Oncol. 2015 Mar;10(3):479-85. 